\title{
APLIKASI METODE GEOLISTRIK RESISTIVITAS UNTUK MENGIDENTIFIKASI LAPISAN BAWAH PERMUKAAN JALAN RASAU JAYA, KABUPATEN KUBU RAYA
}

\author{
Yupensius Febi Ariputra ${ }^{1}$, Yoga Satria Putra ${ }^{1}$, Muhardi ${ }^{1 *}$ \\ ${ }^{1}$ Program Studi Geofisika, Fakultas Matematika dan Ilmu Pengetahuan Alam, Universitas Tanjungpura, Pontianak, 78124, \\ Indonesia \\ *e-mail: muhardi@physics.untan.co.id
}

\begin{abstract}
ABSTRAK
Jalan Rasau Jaya Kabupaten Kubu Rayaberpotensi mengalami kerusakan karena dibangun di atas lapisan yang diduga kurang kompak. Tujuan penelitian ini adalah untuk mengidentifikasi lapisan bawah permukaan di sekitar Jalan Rasau Jaya. Penelitian ini menggunakan metode geolistrik resistivitas dengan konfigurasi Wenner. Metode ini dapat mengidentifikasi sebaran nilai resistivitas bawah permukaan secara lateral. Nilai resitivitas yang diperoleh dijadikan acuan dalam mengidentifikasi lapisan bawah permukaan. Pengukuran dilakukan dengan mengaplikasikan 4 (empat) lintasan dengan panjang masing-masing $141 \mathrm{~m}$, dan jarak antar elektroda sejauh $3 \mathrm{~m}$. Hasil penelitian menunjukkan bahwa sebaran nilai resistivitas di lokasi penelitian sebesar 2 - $584 \Omega$ m hingga kedalaman 23,6 m. Hasil interpretasi menunjukkan bahwa lapisan bawah permukaan terdiri dari 3 (tiga) lapisan. Lapisan pertama mempunyai nilai resistivitas 260 - $584 \Omega$ m yang diinterpretasi sebagai pasir dan kerikil. Lapisan kedua mempunyai nilai resistivitas $11,1-259 \Omega$ m yang diinterpretasi sebagai lapisan lempung berpasir. Lapisan ketiga mempunyai nilai resistivitas 2,0 - 10,1 $\Omega \mathrm{m}$, yang diinterpretasi sebagai lapisan akuifer.
\end{abstract}

Kata Kunci: Metode Geolistrik Resistivitas; Jalan Rasau Jaya; Kubu Raya; Wenner.

\section{ABSTRACT}

[Title: Application of the Geoelectrical Resistivity Method to Identify Subsurface Layers of Jalan Rasau Jaya, Kubu Raya Regency] Jalan Rasau Jaya, Kubu Raya Regency can damage because it is built on a layer that is predicted to be not solid. The study aims to identify the subsurface layer on Jalan Rasau Jaya. This study uses the geoelectrical resistivity method with Wenner configuration. This method can determine the distribution of subsurface resistivity values laterally. So the resistivity value is used as a reference in identifying the subsurface layer. Measurements applying fourlines with a length of $141 \mathrm{~m}$ each, and the distance between the electrodes is $3 \mathrm{~m}$. The results showed that the distribution of resistivity values at the study site was 2-584 $\mathrm{m}$ to a depth of $23.6 \mathrm{~m}$. The interpretation result shows that the subsurface layer consists of three layers. The first layer has a resistivity value of $260-584 \Omega \mathrm{m}$, interpreted as sand and gravel. The second layer has a resistivity value of $11.1-259 \Omega \mathrm{m}$, interpreted as a sandy clay layer. And the third layer has a resistivity value of $2.0-10.1 \Omega \mathrm{m}$, interpreted as an aquifer layer.

Keywords: Geoelectrical Resistivity Method; Jalan Rasau Jaya; Kubu Raya; Wenne.

\section{PENDAHULUAN}

Propinsi Kalimantan Barat (Kalbar) merupakan daerah terluas kedua di pulau kalimantan yang mempunyai ekosistem gambut dengan luas total sekitar 1.729.980 Ha. Pada tahun 2018, tercatat luas gambut di Provinsi Kalbar adalah 1.543.752 Ha (Agus \& Subiksa, 2008). Jalan raya yang dibangun di lahan gambut atau lapisan yang tidak kompak diprediksi akan lebih cepat mengalami kerusakan.Misalnya jalan yang dibangun di Kecamatan Rasau Jaya Kabupaten Kubu Raya. Hal ini disebabkan karena tanah gambut memiliki struktur yang bersifatcompressible, yaitu lapisan yang memiliki potensi untuk mengalami settlement atau penurunan, apalagi jika selalu diberi beban atas di permukaan lapisan tersebut(Muliadi et al., 2019).
Informasi struktur bawah permukaan sangat diperlukandalam melakukan analisis dengan tujuan untuk mengetahui penyebab adanya kerusakan pada jalan raya. Selain itu, juga untuk meningkatkan ketelitian dalam pembuatan pondasi jalan pada lahan gambut.Upaya ini merupakan salah satu solusi dari permasalahan dalam perencanaan pembangunan atau perbaikanjalan raya. Kajian awal terhadap struktur bawah permukaan berguna untuk mengetahui daya dukung lapisan bawah permukaan, sehingga kekuatan jalan dapat disesuaikan dengan kemungkinan beban kendaraan yang melewatinya.

Berdasarkan pengamatan di lapangan, kondisi Jalan Rasau Jaya telah mengalami kerusakan di beberapa bagian ruas jalan. Indikasi ini diperlihatkan dengan adanya permukaan jalan yang agak bergelombang. Penelitian mengenai lapisan bawah permukaan 
tanah dapat dilakukan dengan menggunakan metode geolistrik resistivitas. Metode ini mengidentifikasi sebaran nilai resistivitas bawah permukaan. Konfigurasi elektroda yang digunakan dalam penelitian ini adalah konfigurasi Wenner. Tujuan penggunaan konfigurasi ini adalah agar dapat mengidentifikasi sebaran resistivitas secara lateral atau mapping (Dewi et al., 2020).

Penelitian untuk mengetahui penyebab kerusakan beberapa ruas jalan, terutama yang diakibatkan oleh kondisi struktur lapisan bawah permukaan yang diduga kurang kompak. Jenis lapisan ini diidentifiki berdasarkan sebaran nilai resistivitas. Batas antara lapisan satu dengan yang lain akan menunjukkan kontras tertentu karena tersusun atas material yang berbeda. Lapisan bawah permukaan sangat mempengaruhi daya dukung jalan yang sedang dibagun. Sedangkan daya dukung ini sangat dipengaruhi oleh jenis dan kepadatan tanah. Identifikasi sebaran nilai resistivitas akan membantu dalam mengidentifikasi lapisan tanah terutama jenis lapisan yang kurang kompak, sehingga dapat diprediksi kemampuan lapisan tersebut jika akan diberikan beban di atasnya (Fajania et al., 2021).

Metode geolistrik resistivitas dapat digunakan untuk mengidentifikasi besaran fisis berupa resistivitas (tahanan jenis) lapisan bawah permukaan. Nilai resistivitas ini menggambarkan kemampuan lapisan untuk menghambat aliran arus listrik. Nilai ini kemudian dijadikan dasar untuk melakukan interpretasi kondisi lapisan bawah permukaan. Penelitian sebelumnya juga telah menggunakan metode geolistrik untuk beberapa kajian, di antaranya adalah untuk mengidentifikasi struktur lapisan bawah permukaan (Anas et al., 2020), lokasi keberadaan sesar (Lutfinur et al., 2015), lapisan tanah keras (Masudi et al., 2021), lapisan akuifer yang mengandung air tanah(Hanifa et al., 2016), dan ketebalan lapisan gambut (Fajania et al., 2021).

\section{METODE}

Penelitian ini dilakukan di Kecamatan Rasau Jaya, Kabupaten Kubu Raya, Kalimantan Barat. Lokasi penelitian dipusatkan di Jalan Rasau Jaya, tepatnya pada koordinat $0^{\circ} 11^{\prime} 33.70^{\prime \prime}$ - $0^{\circ} 12^{\prime}$ $07.48^{\prime \prime L S}$ dan $109^{\circ} 23^{\prime} 48.27^{\prime \prime}$ - $109^{\circ} 24^{\prime} 21.45^{\prime \prime}$ BT. Pengambilan data ini dilakukan di 2 lokasi dengan mengaplikasikan 2 lintasan pada masing-masing lokasi pengukuran.Lintasan 1 dan 2 berada di lokasi 1, sedangkan lintasan 3 dan 4 berada di lokasi 2 seperti pada Gambar 1. Setiap lintasan mempunyai jarak antar elektroda $3 \mathrm{~m}$ dan jarak antar lintasan 6 $\mathrm{m}$.

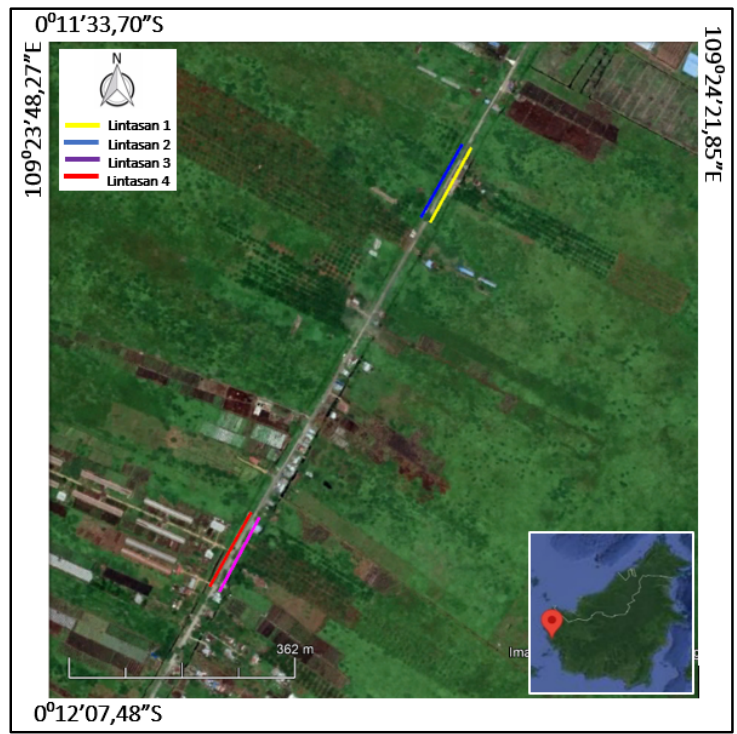

Gambar 1.Desain survei di lokasi penelitian

Penelitian ini menggunakan alat geolistrik berupa Automatic Resistivity System (ARES) 12 V, elektroda arus dan potensial, kabel, aki, dan alat tulis. Proses pengambilan data dilakukandengan cara menginjeksi-kan arus listrik di permukaan bumi melalui elektroda arus dan mengukur beda potensial di permukaan melalui elektroda potensial(Everett, 2013). Adapun susunan elektroda arus $\left(C_{1} C_{2}\right)$ dan elektroda potensial $\left(\mathrm{P}_{1} \mathrm{P}_{2}\right)$ pada konfigurasi Wenner diperlihatkan pada Gambar 2. Konfigurasi ini dapat mengidentifikasi nilai resistivitas secara lateral (Dewi et al., 2020). Elektroda arus dan elektroda potensial diposisikan dengan jarak $a$.

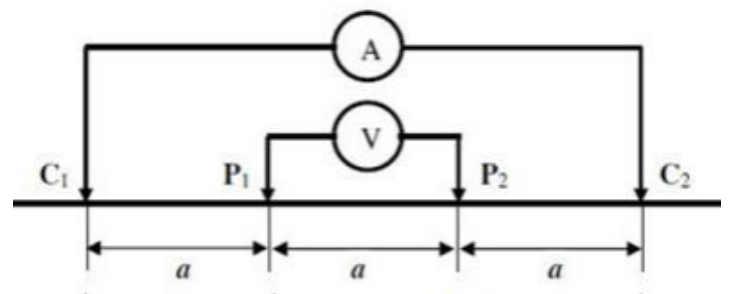

Gambar 2. Susunan elektroda pada konfigurasi Wenner(Milsom, 2003).

Arus listrikIyang diinjeksikan akan mengalir pada medium lapisan bawah permukaan, sehingga beda potensial $V$ di antara kedua ujung medium tersebut dipengaruhi oleh kemampunanya mengham-bat arus listrik (resistansi $R$ ). Sedangkan nilai resistansi ini sangat bergantung dari geometri medium (panjang $L$ dan luas permukaan $A$ ) dan nilai resistivitas $\rho$. Ilustrasi aliran arus pada sebuah medium homogen diperlihatkan pada Gambar 3. 


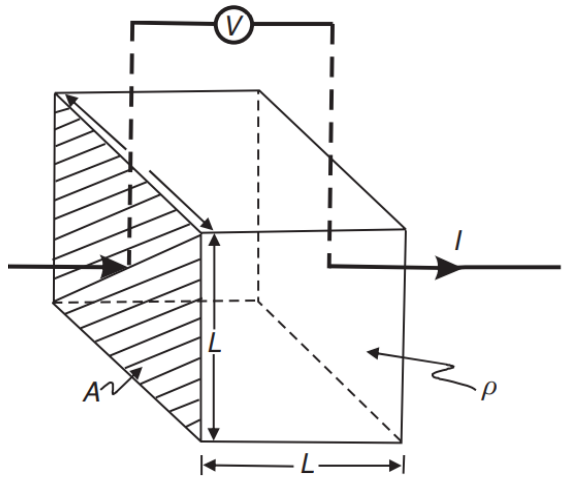

Gambar 3. Ilustrasi aliran arus listik pada sebuah medium homogen (Reynold, 2011)

Resistivitas yang diperoleh merupakan resistivitas semu yang diperoleh dari pembacaan nilai potensial di permukaan dengan anggapan bahwa medium tersebut homogen(Telford et al., 1990). Resistivitas semu $\rho_{a}$ dirumuskan dengan persamaan (1) berikut :

$$
\rho_{a}=\kappa \frac{V}{I}
$$

Dengan $V$ merupakan beda potensial antara $\mathrm{P}_{1}$ dan $\mathrm{P}_{2}$ (Volt), I merupakan besarnya arus listrik yang diinjeksikan melalui $\mathrm{C}_{1}$ dan $\mathrm{C}_{2}$ (Ampere), dan $\kappa$ adalah faktor geometri (m). Adapun Faktor geometri konfigurasi Wenneryaitu:

$$
\kappa=2 \pi a
$$

Tabel 1.Nilai resistivitas beberapa material(Telford et al., 1990; Lowrie, 2007)

\begin{tabular}{lc}
\hline \multicolumn{1}{c}{ Material } & $\begin{array}{c}\text { Resistivitas } \\
(\Omega \mathrm{m})\end{array}$ \\
\hline Udara & - \\
Kerikil kering & $600-1000$ \\
Aluvium & $10-800$ \\
Kerikil & $100-600$ \\
Lempung & $1-100$ \\
Lempung berpasir & $80-105$ \\
Pasir & $1-1000$ \\
Pirit & 0.01 \\
Kwarsa & $500-800000$ \\
Granit & $200-10000$ \\
Basal & $200-10000$ \\
Gamping & $500-10000$ \\
Batu pasir & $200-8000$ \\
Air Tanah & $0.5-300$ \\
Air Asin & 0.2 \\
Magnetit & $0.01-1000$ \\
\hline
\end{tabular}

Tahap selanjutnya adalah melakukan inversi terhadap nilai resistivitas semu sehingga diperoleh penampang resistivitas yang sebenarnya di lokasi penelitian. Kemudian proses interpretasi dilakukan dengan memperhatikan kondisi geologi setempat dan mengacu pada nilai resistivitas yang terdapat pada Tabel 1 .

\section{HASIL DAN PEMBAHASAN}

Keempat lintasan umumnya berarah barat daya - timur laut. Titik awal lintasan pertama berada pada koordinat $00^{\circ} 11^{\prime} 38.67^{\prime \prime} \mathrm{LS}$, $109^{\circ} 24^{\prime} 09.68^{\prime \prime}$ BT dan titik akhir berada pada koordinat $00^{\circ} 11^{\prime} 42.66^{\prime \prime} \mathrm{LS}, \quad 109^{\circ} 24^{\prime} 07.43^{\prime \prime} \mathrm{BT}$. Titik awal lintasan kedua berada pada koordinat $00^{\circ} 11^{\prime} 38.55^{\prime \prime} \mathrm{LS}, 109^{\circ} 24^{\prime} 09.54^{\prime \prime}$ BT dan titik akhir berada pada koordinat $00^{\circ} 11^{\prime} 42.49^{\prime \prime} \mathrm{LS}$, $109^{\circ} 24^{\prime} 07.16^{\prime \prime}$ BT. Titik awal lintasan ketiga berada pada koordinat $00^{\circ} 11^{\prime} 57.74^{\prime \prime} \mathrm{LS}, 109^{\circ} 23^{\prime} 58.75^{\prime \prime} \mathrm{BT}$ dan titik akhir berada pada koordinat $00^{\circ} 12^{\prime} 01.80^{\prime \prime} \mathrm{LS}, \quad 109^{\circ} 23^{\prime} 56.58^{\prime \prime} \mathrm{BT}$. Sedangkan titik awal lintasan pertama berada pada koordinat $00^{\circ} 11^{\prime} 57.67^{\prime \prime} \mathrm{LS}, 109^{\circ} 23^{\prime} 58.52^{\prime \prime}$ BT dan titik akhir berada pada koordinat $00^{\circ} 12^{\prime} 01.72^{\prime \prime} \mathrm{LS}$, $109^{\circ} 23^{\prime} 56.38^{\prime \prime}$ BT.

Gambar 4 menunjukkan penampang resistivitas 2D keempat lintasan dengan sebaran nilai resistivitas 2,0 - $584 \Omega \mathrm{m}$ hingga kedalaman 23,6 m. Berdasarkan peta geologi lembar Kalimantan Barat, lokasi penelitian ini berada pada formasi endapan permukaan yang tersusun atas kerikil, pasir, lanau, lumpur, endapan sungai, pantai, danau, rawa, dan aluvium (Pieter \& Supriatna, 1990). Hasil interpretasi menunjukkan bahwa lapisan bawah permukaan diduga mempunyai 3 (tiga) lapisan yang masing-masing ditunjukkan dengan warna jingga, hijau, dan biru seperti yang diperlihatkan pada Tabel 2. Nilai resistivitas $2,0-10,1 \Omega \mathrm{m}$ (warna biru muda hingga biru tua) diduga sebagai lapisan akuifer berupa pasir yang mengandung air tanah. Nilai resistivitas 10,1 - $259 \Omega \mathrm{m}$ (warna hijau muda hingga hijau tua) diduga sebagai lempung berpasir. Nilai resistivitas 259 - $584 \Omega \mathrm{m}$ (warna jingga muda hingga jingga tua) diduga pasir kerikil.

Selain itu, hasil interpretasi pada penampang resistivitas 2D di lokasi penelitian belum menunjukkan adanya lapisan yang mempunyai nilai resistivitas yang cukup tinggi. Sehingga batuan dasar (bedrock) belum bisa diidentifikasi, karena batuan dasar diindikasikan dengan nilai resistivitas yang relatif tinggi jika dibandingkn dengan lapisan yang lain. 


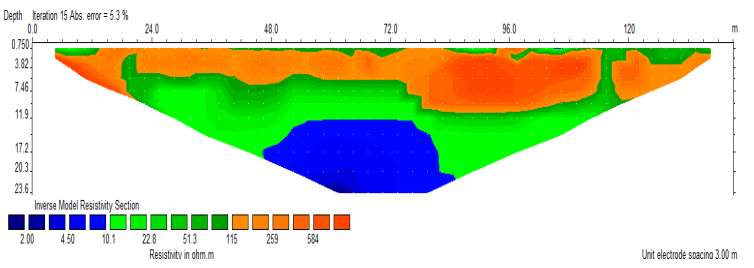

[a]

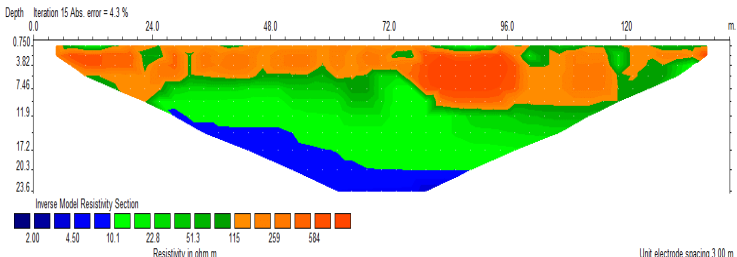

[b]

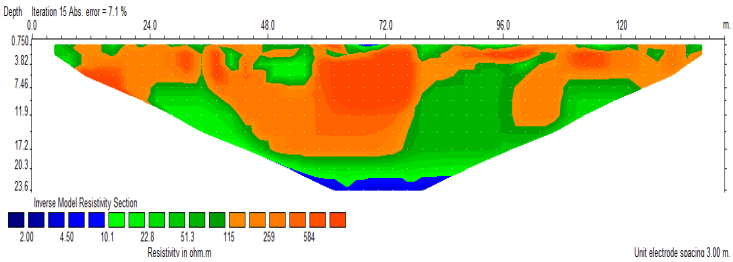

[C]

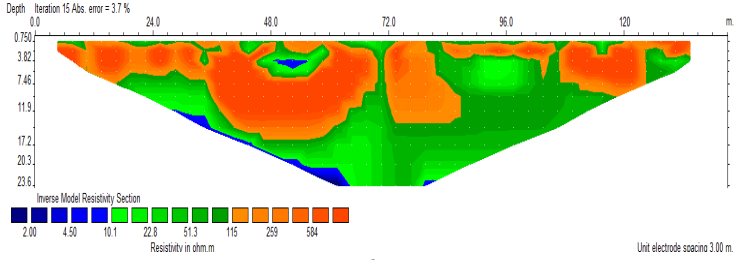

[d]

Gambar 4. Penampang resistivitas 2D; [a] lintasan pertama, [b] lintasan kedua, [c] lintasan ketiga, dan [d] lintasan keempat

Tabel 2. Interpretasi lapisan bawah permukaan

\begin{tabular}{ccl}
\hline Warna & $\begin{array}{c}\text { Resistivitas } \\
(\mathbf{\Omega m})\end{array}$ & \multicolumn{1}{c}{ lapisan } \\
\hline$\square \square \square \square$ & $2,00-10,1$ & Akuifer \\
\hline$\square \square \square \square \square$ & $10,1-259$ & Lempung berpasir \\
\hline$\square \square \square \square \square$ & $259-584$ & Pasir kerikil \\
\hline
\end{tabular}

Hasil interpretasi lapisan bawah permukaan berupa pasir, kerikil, dan lempung berpasir merupakan lapisan yang cenderung tidak kompak. Keberadaan lapisan ini diduga menjadi penyebab berkurangnya daya dukung dari sebagian ruas Jalan Rasau Jaya. Oleh karena itu, masih ditemukan sebagian permukaan ruas jalan yang bergelombang di beberapa titik. Namun persoalan ini dapat diatasi dengan memperbaiki konstruksi jalan yaitu melakukan pengerasan pada jalan tersebut dengan maksimal, khususnya pada saat perbaikan ruas jalan yang rusak.

\section{KESIMPULAN DAN SARAN}

Dari hasil yang diperoleh dapat disimpulkan bahwa metode geolistrik resistivitas dengan konfigurasi Wenner telah mengidentifikasi sebaran nilai resistivitas di sekitar Jalan Rasau Jaya sebesar 2 - $584 \Omega \mathrm{m}$ hingga kedalaman 23,6 m. Hasil interpretasi menunjukkan bahwa lapisan bawah permukaan terdiri dari 3 (tiga) lapisan. Lapisan pertama mempunyai nilai resistivitas 260 - $584 \Omega m$ yang diinterpretasi sebagai pasir dan kerikil. Lapisan kedua mempunyai nilai resistivitas $11,1-259 \Omega \mathrm{m}$ yang diinterpretasi sebagai lapisan lempung berpasir. Lapisan ketiga mempunyai nilai resistivitas 2,0 10,1 $\Omega \mathrm{m}$, yang diinterpretasi sebagai lapisan akuifer.

Saran kepada peneliti selanjutnya agar dapat memperbanyak titik lokasi pengukuran sehingga mampu menggambarkan kondisi bawah permukaan Jalan Rasau Jaya secara menyeluruh. Selain itu, dapat dilakukan survei geolistrik dengan metode sounding, agar dapat mengidentifikasi sebaran nilai resistivitas secara vertikal, sehingga dapat diidentifikasi lapisan dengan kedalaman yang lebih besar dari penelitian ini. Juga dapat dilakukan pengeboran untuk memvalidasi hasil interpretasi terhadap lapisan bawah permukaan.

\section{UCAPAN TERIMAKASIH}

Penulis mengucapkanterima kasih kepada kepala Laboratorium Geofisika dan Sistem Informasi Geografis, Fakultas MIPA Universitas Tanjungpura, yang telah memfasilitasi penelitian ini terutama dalam perizinan penggunaan alat geolistrik ARES.

\section{DAFTAR PUSTAKA}

Agus, F., \& Subiksa, I. G. M. (2008). Lahan Gambut : Potensi untuk Pertanian dan Aspek Lingkungan. In Balai Penelitian Tanah dan World Agroforestry Centre (ICRAF).

Anas, N. A., Syamsuddin, Harimei, B., \& Nasri, M. (2020). Identifikasi Struktur Bawah Permukaan di Sekitar Manifestasi Panas Bumi Reatoa Kabupaten Maros Menggunakan Survey Geolistrik Resistivitas. Jurnal Geocelebes, 4(1), 23-32.

Dewi, I. K., Resta, I. L., \& Juventa. (2020). Aplikasi Geolistrik Konfigurasi Wenner dalam Mendeteksi Pencemaran Air Tanah Akibat Gambut pada Desa Sungai Terap. Journal Online of Physics, 6(1), 44-51.

Everett, M. E. (2013). Near-Surface Applied Geophysics. Cambridge University Press.

Fajania, R., Arman, Y., \& Muhardi. (2021). Pendugaan Ketebalan Lapisan Gambut di 
Sekitar Jalan Reformasi Kota Pontianak Menggunakan Metode Geolistrik Tahanan Jenis. Jurnal Geocelebes, 5(1), 16-22.

Hanifa, D., Sota, I., \& Siregar, S. S. (2016). Penentuan Lapisan Akuifer Air Tanah dengan Metode Geolistrik Konfigurasi Schlumberger di Desa Sungai Jati Kecamatan Mataraman Kabupaten Banjar Kalimantan Selatan. Jurnal Fisika FLUX, 13(1), 30-39.

Lowrie, W. (2007). Fundamental of Geophysics (Second Edition). Cambridge University Press.

Lutfinur, I., Khumaedi, \& Susanto, H. (2015). Identifikasi Sesar Bawah Permukaan Menggunakan Metode Geolistrik Konfigurasi Schlumberger (Studi Kasus Sungai Opak Yogyakarta). Indonesian Journal of Applied Physics, 5(2), 10-24.

Masudi, Nurhasanah, \& Muhardi. (2021). Identifikasi Kedalaman Lapisan Tanah Keras Menggunakan Metode Geolistrik Tahanan Jenis (Studi Kasus: Jalan Perdana Kota Pontianak). Jurnal Ilmu Dan Inovasi Fisika, 5(1), 59-64.

Milsom, J. (2003). Field Geophysics (Third Edition). Wiley.

Muliadi, Zulfian, \& Muhardi. (2019). Identifikasi Ketebalan Tanah Gambut Berdasarkan Nilai Resistivitas 3D: Studi Kasus Daerah Tempat Pembuangan Akhir Batu Layang Kota Pontianak. Positron, 9(2), 86-94.

Pieter, P. E., \& Supriatna, S. (1990). Peta Geologi Kalimantan Barat. Pusat Penelitian dan Pengembangan Geologi.

Reynold, J. M. (2011). An Introduction to Applied and Environmental Geophysics 2nd Edition. In Library of Congress.

Telford, W. M., Geldart, L. P., \& Sheriff, R. E. (1990). Applied Geophysics (Second Edition). Cambridge University Press. 